\title{
Relationship between Levels of Pre-Stroke Physical Activity and Post-Stroke Serum Insulin-Like Growth Factor I
}

\author{
N. David Åberg ${ }^{1,2, *(\mathbb{D})}$, Gustaf Gadd ${ }^{1,2}$, Daniel Åberg ${ }^{1,2}$, Peter Hällgren ${ }^{2}$, \\ Christian Blomstrand ${ }^{3}$, Katarina Jood ${ }^{3}$, Michael Nilsson ${ }^{4,5}$, Fredrick R. Walker ${ }^{4,5}$, \\ Johan Svensson $^{1}$, Christina Jern ${ }^{6,7}$ and Jörgen Isgaard ${ }^{1,4}$ \\ 1 Department of Internal Medicine, Institute of Medicine, The Sahlgrenska Academy, University of \\ Gothenburg, SE-41345 Gothenburg, Sweden; gustaf.gadd@vgregion.se (G.G.); \\ daniel.aberg@medic.gu.se (D.Å.); johan.svensson@medic.gu.se (J.S.); jorgen.isgaard@medic.gu.se (J.I.) \\ 2 Region Västra Götaland, Sahlgrenska University Hospital, Gothenburg SE-41345, Sweden; \\ peter.hallgren@vgregion.se \\ 3 Department for Clinical Neuroscience, Institute of Neuroscience and Physiology, The Sahlgrenska Academy, \\ University of Gothenburg, SE-405 30 Gothenburg, Sweden; christian.blomstrand@neuro.gu.se (C.B.); \\ katarina.jood@neuro.gu.se (K.J.) \\ 4 School of Biomedical Sciences and Pharmacy and the Priority Research Centre for Stroke and Brain Injury, \\ the University of Newcastle, University Dr, Callaghan, NSW 2308, Australia; \\ michael.nilsson@newcastle.edu.au (M.N.); rohan.walker@newcastle.edu.au (F.R.W.) \\ 5 Hunter Medical Research Institute, Lot 1, Kookaburra Cct, New Lambton Heights, NSW 2305, Australia \\ 6 Department of Laboratory Medicine, Institute of Biomedicine, The Sahlgrenska Academy, University of \\ Gothenburg, SE-41345 Gothenburg, Sweden; christina.jern@neuro.gu.se \\ 7 Department of Clinical genetics and genomics, Sahlgrenska University Hospital, \\ SE-41345 Gothenburg, Sweden \\ * Correspondence: david.aberg@medic.gu.se; Tel.: +46-31-342-8422
}

Received: 31 January 2020; Accepted: 2 March 2020; Published: 4 March 2020

\begin{abstract}
Physical activity (PA) and insulin-like growth factor I (IGF-I) have beneficial effects for patients who have suffered an ischemic stroke (stroke). However, the relationship between the levels of PA and IGF-I after stroke has not been explored in detail. We investigated the pre-stroke PA level in relation to the post-stroke serum IGF-I (s-IGF-I) level, at baseline and at 3 months after the index stroke, and calculated the change that occurred between these two time-points ( $\triangle$ IGF-I). Patients $(N=380 ; 63.4 \%$ males; mean age, 54.7 years) with data on 1-year leisure-time pre-stroke PA and post-stroke s-IGF-I levels were included from the Sahlgrenska Academy Study on Ischemic Stroke (SAHLSIS). Stroke severity was assessed using the National Institutes of Health Stroke Scale (NIHSS). Pre-stroke, leisure-time PA was self-reported as PA1-4, with PA1 representing sedentary and PA2-4 indicating progressively higher PA levels. Associations between s-IGF-I and PA were evaluated by multiple linear regressions with PA1 as the reference and adjustments being made for sex, age, history of previous stroke or myocardial infarctions, cardiovascular risk factors, and stroke severity. PA correlated with baseline s-IGF-I and $\triangle$ IGF-I, but not with the 3-month s-IGF-I. In the linear regressions, there were corresponding associations that remained as a tendency (baseline s-IGF-I, $p=0.06$ ) or as a significant effect ( $\triangle \mathrm{IGF}-\mathrm{I}, p=0.03)$ after all the adjustments. Specifically, for each unit of PA, $\triangle$ IGF-I increased by 9.7 (95\% CI 1,1-18.4) ng/mL after full adjustment. This supports the notion that pre-stroke PA is independently related to $\triangle \mathrm{IGF}-\mathrm{I}$.
\end{abstract}

Keywords: stroke; cerebrovascular disease; insulin-like growth factor I; ischemic stroke; stroke severity; physical activity 


\section{Introduction}

Stroke is a condition that is associated with high costs for the healthcare system, with the financial burden and suffering being significantly higher in cases of moderate and severe stroke than in mild cases [1]. To improve stroke prevention, knowledge of key risk factors, especially those that are modifiable, such as physical activity (PA), is essential. Insulin-like growth factor I (IGF-I) has neuroprotective effects and promotes brain plasticity in a positive fashion after brain injuries [2]. In line with this, higher serum insulin-like growth factor I (s-IGF-I) levels are associated with improved recovery after ischemic stroke, hereinafter referred to as stroke [3-7]. Moreover, a low level of s-IGF-I is a risk factor for the occurrence of stroke [8]. The expression of s-IGF-I is upregulated by growth hormone $(\mathrm{GH})$ from the pituitary, although IGF-I is also related to other factors, showing a negative relationship with age and insulin resistance and a positive relationship with PA [9,10].

Studies that have investigated the relationship between stroke and s-IGF-I have produced variable findings of increased [5,11], unchanged [6], and decreased post-stroke levels of s-IGF-I [3,12]. It appears that this variability is largely attributable to differently matched controls (or no matching at all) at the time of the post-stroke sampling or to whether there was an intra-individual collection of serial serum samples. Data from our group and others indicate that there is at least some increase in the level of s-IGF-I during the first days after stroke [5,11], whereas the s-IGF levels are lower 3 months later [5]. As PA [13,14] and s-IGF-I [3-7] each have beneficial effects following stroke and their mutual relationship after stroke has been scarcely explored, the s-IGF-I response with respect to pre-stroke PA may be of relevance to recovery after brain injuries. The notion that PA is related to circulating IGF-I in terms of stroke is also underlined by experimental data showing that exercise-induced recovery after a chemical insult to the brain is attenuated by the administration of anti-IGF-I antibody-containing serum [15]. Furthermore, it appears that not only the s-IGF-I level per se but also the dynamic post-stroke decrease in s-IGF-I is able to predict stroke outcome [7].

The reports linking s-IGF-I to exercise and PA levels, including the situation of post-injury brain recovery after a chemical insult, prompted us to investigate the self-reported pre-stroke PA levels and post-stroke s-IGF-I responses in patients with stroke. In the present study, we investigated the potential associations between pre-stroke PA and post-stroke s-IGF-I, at baseline (baseline s-IGF-I) and at 3 months post-stroke (3-month s-IGF-I), and including the change in s-IGF-I calculated between these two time-points $(\Delta \mathrm{IGF}-\mathrm{I})$, and we examined whether these associations were retained in different multiple linear regression models.

\section{Results}

\section{Pre-stroke Physical Activity and Post-stroke s-IGF-I}

The baseline characteristics of the 380 patients included in this study are summarized in Table 1. The cardiovascular risk factors of diabetes, hypertension, and smoking were commonly observed in this cohort, as before $[5,7,16,17]$. The pre-stroke PA level of the studied cohort was skewed towards a lower level of PA, with PA1 and PA2 constituting $82.9 \%$ of the whole cohort and with very few of the participants being in the PA4 group, as shown in Table 1. Stroke severity (baseline NIHSS) was not correlated with pre-stroke PA. Significant crude negative correlations between PA and body mass index (BMI), diabetes, and smoking were noted (Table 1). However, although there was a significant relation between s-IGF-I and PA (Figure 1), none of the IGF-I variables (baseline s-IGF-I, 3-month s-IGF-I, or $\triangle \mathrm{IGF-I})$ correlated with BMI $(r=-0.034, p=0.52 ; r=0.016, p=0.77 ; r=-0.029, p=0.59$, respectively). 
Table 1. Baseline parameters and crude correlations vs. physical activity (PA).

\begin{tabular}{|c|c|c|c|c|c|}
\hline \multirow{2}{*}{ Parameter } & \multirow{2}{*}{ Value } & \multirow{2}{*}{$\begin{array}{c}\text { Subjects } \\
\mathbf{N}\end{array}$} & \multirow{2}{*}{$\begin{array}{c}\text { Missing } \\
\text { N (\%) }\end{array}$} & \multicolumn{2}{|c|}{ Correlation (vs. PA) } \\
\hline & & & & $r$ & $p$ \\
\hline Patients with stroke (N) & 380 & 380 & $0(0)$ & N/A & $\mathrm{N} / \mathrm{A}$ \\
\hline Age, years, median (IQR) & $57.0(49.8-63.0)$ & 380 & $0(0)$ & -0.07 & 0.13 \\
\hline Male/female, N (male \%) & $241 / 139(63.4)$ & 380 & $0(0)$ & -0.091 & 0.078 \\
\hline History of stroke, N (\%) & $71(18.6)$ & 380 & $0(0)$ & -0.152 & 0.006 \\
\hline History of cardiovascular disease, N (\%) & $117(30.7)$ & 380 & $0(0)$ & -0.018 & 0.75 \\
\hline BMI, kg/m², median (IQR) & $25.7(23.6-28.7)$ & 377 & $3(0.8)$ & -0.122 & 0.018 \\
\hline Diabetes, N (\%) & $70(18.4)$ & 380 & $0(0)$ & -0.179 & $<0.001$ \\
\hline Hypertension, N (\%) & $206(54.2)$ & 376 & $4(1.1)$ & -0.051 & 0.32 \\
\hline Current smoking, N (\%) & $147(38.7)$ & 380 & $0(0)$ & -0.164 & 0.001 \\
\hline LDL, mmol/L, median (IQR) & $3.3(2.6-4.0)$ & 342 & $38(10)$ & -0.015 & 0.79 \\
\hline Imputed LDL, mmol/L, median (IQR) & $3.3(2.7-3.9)$ & 380 & $0(0)$ & -0.016 & 0.76 \\
\hline 3-month mRS, median (IQR) & $2(1-2)$ & 359 & $21(5.5)$ & -0.029 & 0.59 \\
\hline PA, median (IQR) & $2(2-2)$ & 380 & $0(0)$ & N/A & N/A \\
\hline PA $1, \mathrm{~N}(\%)$ & $3.54(1.6-9.56)$ & $76(20.0)$ & $0(0)$ & $\mathrm{N} / \mathrm{A}$ & N/A \\
\hline PA 2, N (\%) & $2.46(0.74-6.33)$ & $\begin{array}{c}239 \\
(62.9)\end{array}$ & $0(0)$ & $\mathrm{N} / \mathrm{A}$ & $\mathrm{N} / \mathrm{A}$ \\
\hline PA 3, N (\%) & $2.46(1.6-10.2)$ & $57(15.0)$ & $0(0)$ & N/A & N/A \\
\hline PA $4, \mathrm{~N}(\%)$ & $2.46(1.82-12.35)$ & $8(2.1)$ & $0(0)$ & N/A & N/A \\
\hline Stroke severity, NIHSS, median (IQR) & $2.89(1.17-7.62)$ & 380 & $0(0)$ & -0.017 & 0.75 \\
\hline
\end{tabular}

Footnotes: The numbers of subjects $(N)$ and percentages $(\%)$ are given relative to the whole cohort $(N=380)$. $p$-values $<0.05$ are indicated in bold. Crude correlations, according to the method of Spearman (rho values, $r$; and $p$-values, $p$ ), are shown for each parameter vs. PA. History of cardiovascular disease includes myocardial infarctions, peripheral artery disease, and any stroke. IQR, interquartile range; N/A, not applicable; NIHSS, National Institutes of Health Stroke Scale; NS, not significant; LDL, low-density lipoprotein; mRS, modified Rankin Scale.

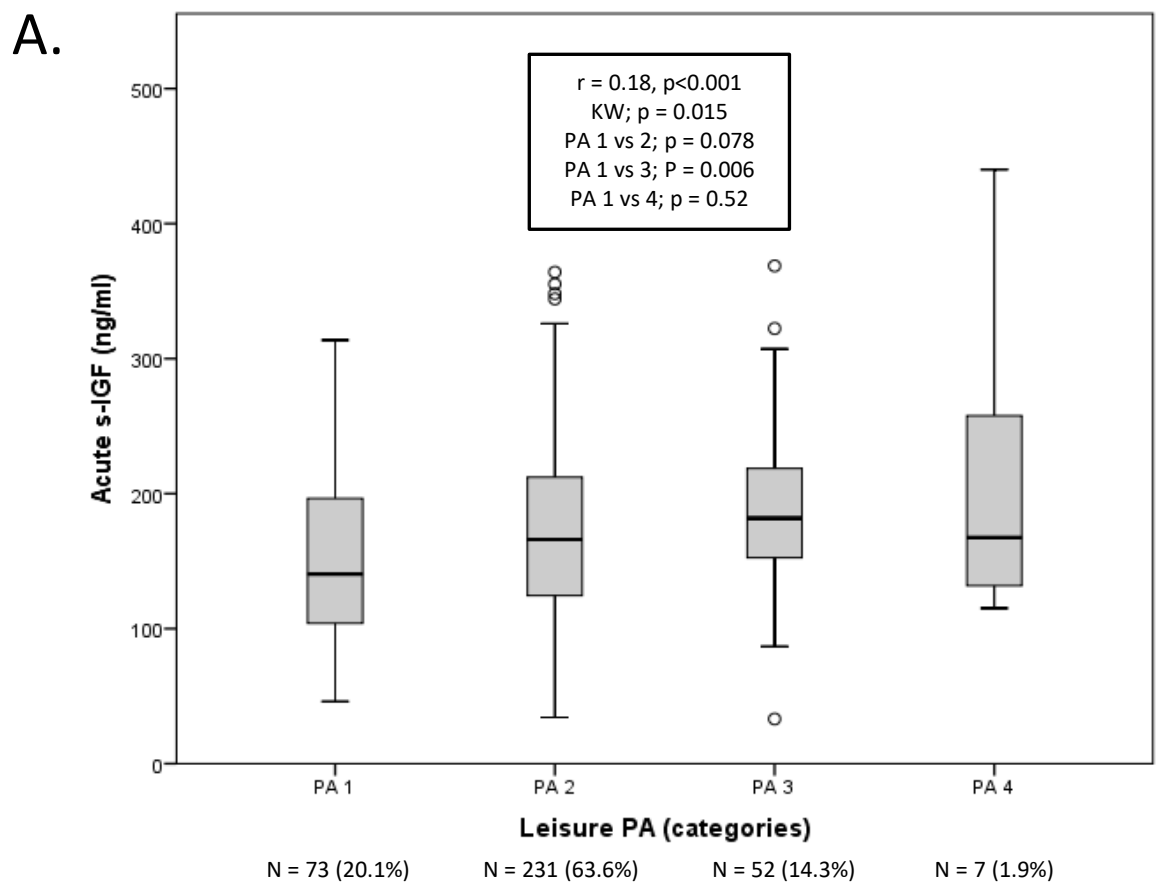

Figure 1. Cont. 


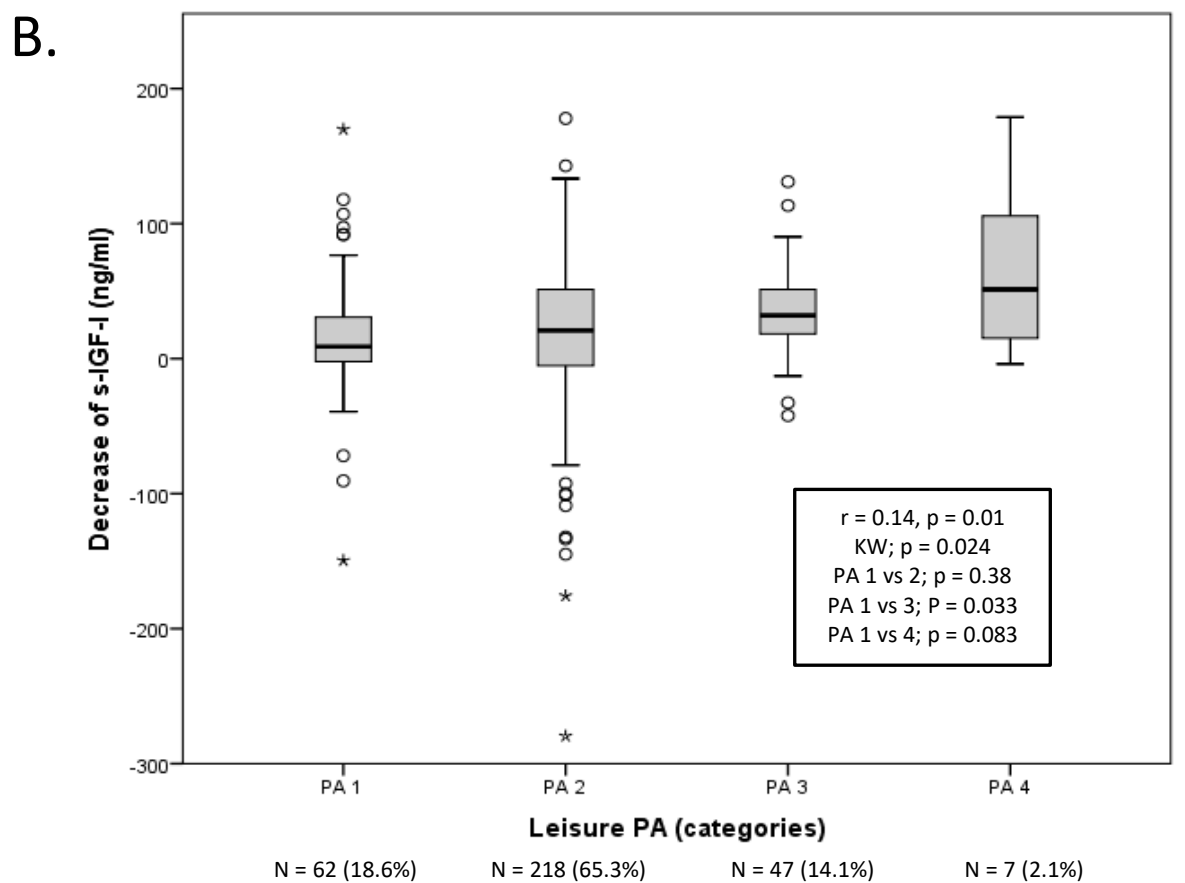

Figure 1. Serum insulin-like growth factor I insulin-like growth factor I (IGF-I) (ng/mL) according to pre-stroke physical activity (PA) levels 1-4, as assessed by Salting-Grimby. (A). Baseline IGF-I according to pre-stroke PA. (B). $\triangle$ IGF-I, according to pre-stroke PA. $\triangle$ IGF-I represents the change (decrease) in serum IGF-I (s-IGF-I) from baseline to 3 months post-stroke. Thus, a greater positive value in the figure represents a greater decrease. Box plots showing the median, interquartile ranges, whiskers, outliers (circles) and extremes (asterisks, see methods). The results of the Spearman correlation are given in the text box (rho, $r$, and $p$-values). The Kruskal-Wallis (KW) overall $p$-value is given as well as $p$-values for the Bonferroni-corrected (for 3 comparisons) comparisons vs. PA1. For baseline s-IGF-I, there were $N=363(95.5 \%)$, and for $\Delta$ IGF-I, there were $N=334(87.8 \%)$, with numbers $(N)$ and relative percentages (\%) for each PA1-4 category given in the Figure.

The median baseline level of s-IGF-I was $164 \mathrm{ng} / \mathrm{mL}$, the median $\Delta \mathrm{IGF}-\mathrm{I}$ was $21.3 \mathrm{ng} / \mathrm{mL}$, and the median 3-month s-IGF-I was $147 \mathrm{ng} / \mathrm{mL}$. As compared to the PA1 group, the baseline s-IGF-I was significantly higher in the PA2 (19\%) and PA3 (30\%) groups, and $\triangle$ IGF-I was significantly higher in the PA3 (260\%) and PA4 (474\%) groups (Figure 1). There were no statistically significant differences in the 3-month s-IGF-I level between the different PA levels (not shown). However, there were statistically significant correlations between PA and the baseline s-IGF-I and $\triangle I G F-I$ (Figure 1), but not with the 3-month s-IGF-I ( $r=0.092, p=0.084)$.

The significant correlations between PA and s-IGF-I (baseline s-IGF-I and $\triangle$ IGF-I) were further assessed by multiple linear regression analyses, as shown in Table 2. In Models 1 and 2, with adjustments made for age, sex, and history of previous stroke or myocardial infarctions, the association between baseline s-IGF-I and PA remained significant, whereas only a tendency towards an association remained after additional adjustments were made for cardiovascular risk factors. The association between $\triangle$ IGF-I and PA, however, remained significant in all of the models (Model 4, $p=0.028$ ). Specifically, with full adjustment (Model 4), for each unit of PA, $\Delta$ IGF-I increased by 9.7 (95\% CI $1,1-18.4) \mathrm{ng} / \mathrm{mL}$. 
Table 2. Linear regression for serum insulin-like growth factor I (s-IGF-I) per increase in pre-stroke physical activity (PA).

\begin{tabular}{lcccc}
\hline Type of s-IGF-I/Regression Model & $\begin{array}{l}\text { B Per Increase in PA } \\
(\mathbf{B}=\mathbf{n g} / \mathbf{m L} \text { s-IGF-I) }\end{array}$ & $\boldsymbol{p}$ & $\mathbf{N}$ (PA1-4) & Partial Correlation \\
\hline Baseline s-IGF-I level & $12.9(2.52-21.9)$ & 0.014 & 363 & 0.13 \\
Model 1 [PA/A/S] & $12.1(2.34-21.8)$ & 0.015 & 363 & 0.13 \\
Model 2 [PA/A/S/history] & $9.7(-0.33-19.8)$ & 0.058 & 356 & 0.10 \\
Model 3 [PA/A/S/history/B/C] & $9.7(-0.38-19.7)$ & 0.059 & 356 & 0.10 \\
Model 4 [PA/A/S/history/B/C/I] & & & & \\
\hline Change in s-IGF-I level (BIGF-I) & $8.9(0.29-17.5)$ & 0.043 & 334 & 0.11 \\
Model 1 [PA/A/S] & $9.3(0.62-18.0)$ & 0.036 & 334 & 0.12 \\
Model 2 [PA/A/S/history] & $9.2(0.36-18.0)$ & 0.041 & 332 & 0.11 \\
Model 3 [PA/A/S/history/B/C] & $9.7(1.1-18.4)$ & 0.028 & 332 & 0.12 \\
Model 4 [PA/A/S/history/B/C/I] &
\end{tabular}

Multiple linear regressions of the baseline and changes in s-IGF-I levels ( $\triangle$ IGF-I) with respect to pre-stroke physical activity (PA). The unstandardized B values (s-IGF-I, ng/mL) with corresponding $95 \%$ confidence intervals (CI) per unit of PA are shown. In addition, the partial correlations for each of the models are given. Models 1-4 are shown with the following successively added adjustments for PA: age (A), sex (S), history of previous stroke and myocardial infarction (history), body mass index (B), traditional cardiovascular covariates (C, see Methods), and initial stroke severity (I).

\section{Discussion}

\subsection{Physical Activity and s-IGF-I}

To the best of our knowledge, this is the first study to demonstrate that PA prior to ischemic stroke is not only associated with the baseline s-IGF-I but also with the magnitude of the decrease in s-IGF-I ( $\triangle$ IGF-I) during the first 3 months after the ischemic event. The associations remained significant in all the multiple regression models for $\triangle \mathrm{IGF}-\mathrm{I}$, as opposed to the attenuated association for PA and baseline s-IGF-I. The finding that the 3-month IGF-I level did not differ significantly between the PA groups implies that post-stroke IGF-I represents an acute response to the ischemic stroke, mainly in terms of the baseline s-IGF-I and $\triangle$ IGF-I values.

Two major discoveries emerge from the present study: 1) the pre-stroke PA association with post-stroke baseline s-IGF-I and $\triangle$ IGF-I shows different attenuations, with only the first association being attenuated (to a tendency) after adjustments for cardiovascular covariates. This may reflect mediation or confounding, although the data within our study do not allow us to discriminate between these two possibilities. Notwithstanding uncertain causality, it appears that post-stroke s-IGF-I is in some way related to PA. In light of the present results, it is noteworthy that $\triangle$ IGF-I has previously been shown to have the strongest association with the beneficial effects on stroke outcome [7]. This may reflect the importance of the response of IGF-I to the acute ischemic event. In particular, decreasing levels in IGF-I, i.e., $\triangle$ IGF-I, post-stroke appears to be associated with good functional outcome after ischemic stroke $[7,11]$. In animal experiments, the degree of physical exercise has been shown to be positively associated with the uptake of circulating IGF-I into the brain in a situation with an injury caused by a chemical insult [15], which has some similarities to stroke. Although this is an observational study without assessment of IGF-I uptake into the brain, the present results are in line with those previous results and support the notion that a high level of PA facilitates high-level uptake of peripheral s-IGF-I, which may be reflected in the rather robust association with $\Delta$ IGF-I. In this aspect, it is of interest to mention that previously we have shown that $\triangle \mathrm{IGF}-\mathrm{I}$ is associated with the most favorable outcome after stroke [7]. Finally, it should be noted that although the causal relationship between PA and s-IGF has been debated [10] and been considered complex [18], an association between s-IGF-I and aerobic fitness and muscular endurance has been demonstrated in healthy individuals [19]. This is also in line with a report showing that the estimated pre-stroke aerobic capacity is crudely correlated with post-stroke s-IGF-I assessed 0-72 $\mathrm{h}$ after the stroke [20], although neither the PA levels per se nor any regressions were analyzed. Furthermore, while several studies have determined that PA prior to stroke is associated with improved outcomes [13,21,22], this is one of the first studies to implicate IGF-I 
as a contributing mechanism. Collectively, these findings suggest that greater consideration should be given to tracking the serum levels of IGF-1 in recovering patients.

\subsection{Strengths and Limitations}

This is a prospective study with dual sample points for the biomarker of interest, IGF-I. Compared with previous studies that have looked at changes in post-stroke IGF-I, the number of patients in the Sahlgrenska Academy Study on Ischemic Stroke (SAHLSIS) cohort is relatively high [11]. However, since the PA levels were skewed towards lower values, there was only a low number of patients with PA4 $(N=8)$, weakening the specific analysis of the effect in that group. Another weakness is the use of self-reported retrospective data collected shortly after an acute stroke, although the Saltin-Grimby Physical Activity Level Scale (SGPALS) is a well-established scale for assessing the history of PA [21,23]. Specifically, in the present study, the level of PA was taken as the self-reported average during the 12 months preceding the index ischemic stroke. Finally, it would be of great interest to have data on post-stroke PA levels and pre-stroke s-IGF-I. However, to investigate the latter, a completely different study design would be required (such as a long-term observational study of a healthy cohort).

\section{Materials and Methods}

\subsection{Subjects and Design}

The design of SAHLSIS has been described previously [5,16]. Briefly, adult patients aged $<70$ years with first-ever or recurrent acute IS were recruited consecutively at four Stroke Units in western Sweden in the period of 1998-2003. However, in the present study, only patients from the Stroke Unit at the Sahlgrenska University Hospital were included, as analyzed previously $(N=407)$ [5]. In addition, in this study, we used data from the patients regarding pre-stroke PA and s-IGF-I for any of the time-points of baseline or 3 months post-stroke $(N=380)$ (Table 1). At inclusion into SAHLSIS, the pre-stroke PA level for the last 12 months before the index stroke was assessed in a questionnaire using a self-report scale, with four levels of PA, the SGPALS, in which PA1 represents sedentary, and PA2 to PA4 representing progressively higher levels of PA [23]. In short, PA2 represents an "active group", PA3 an "intensive group", and PA4, an "elite intensive group"; a more detailed presentation is given in the Supplementary Material.

The s-IGF-I was measured in the acute phase (i.e., early post-stroke, baseline s-IGF-I; at a median of 4 days post-stroke) and at 3 months after the index stroke (3-month s-IGF-I) [5] (see also Supplementary Material, which includes data on variation and detection limits). The change (decrease) in s-IGF-I between baseline and 3 months, $\triangle$ IGF-I, was calculated [7]. Data on sex, age, history of previous stroke and/or myocardial infarctions/peripheral artery disease, body mass index (BMI), conventional vascular risk factors [presence of hypertension, diabetes mellitus, smoking, and concentration of low-density lipoprotein (LDL), $\mathrm{mmol} / \mathrm{L}$ ], and initial stroke severity were recorded and included in the analyses. The severity of stroke in the acute phase was initially assessed according to the Scandinavian Stroke Scale (SSS), expressed as the maximum score during days $0-10$, and this was transformed into the more frequently used NIHSS according to the validated algorithm of NIHSS $=25.68-0.43 \times$ SSS [24]. BMI, hypertension, diabetes, and smoking were defined as described previously $[5,7,16,17]$, and functional outcome 3 months and 2 years after IS was assessed using the modified Rankin Scale (mRS); all of these details are further described in Supplementary Materials. Written informed consent was obtained from the patient or next of kin. This study was approved by the Ethics Committee of the University of Gothenburg (\#Ö469-99, 03/02/2000).

\subsection{Statistical Analysis}

Continuous data are presented as median values and interquartile ranges (IQR) due to the non-parametric distribution. Box-plots are given according to the Tukey distribution; medians, 25th-75th percentiles, and ranges (whiskers) are all defined as values between the 25th percentile 
$-[1.5 \times$ interquartile range $(\mathrm{IQR})]$ and the 75 th percentile $+(1.5 \times \mathrm{IQR})$, with outliers (circles) and extremes (asterisks). The Shapiro-Wilk test was performed for testing normality. The Kruskal-Wallis H-test, followed by a series of pairwise Bonferroni-corrected Mann-Whitney $U$-tests, was performed. Spearman correlation was used for testing correlations between PA and the various parameters (Tables 1 and 2). Multiple linear regression was used for determining unstandardized B-values (equivalent to s-IGF-I ng/mL at baseline or as the change in s-IGF-I level at 3 months, $\triangle$ IGF-I) and $95 \%$ confidence interval (CI) per unit of pre-stroke PA level. Adjustments were made for sex (S), age (A), history of stroke or myocardial infarction (history), BMI (B), conventional vascular risk factors (hypertension, diabetes, smoking, LDL) (C), and initial stroke severity (I). For LDL, which had the most missing values, imputation was used to replace the missing values with the mean LDL value. The statistical significance level was set at a two-tailed $p$-value $<0.05$. Statistical analyses were performed using the IBM $^{\circledR}$ SPSS $^{\circledR}$ ver. 25 software (SPSS Inc., Chicago, IL, USA).

\section{Conclusions}

The present study reveals an independent association between pre-stroke PA and post-stroke s-IGF-I. Of the IGF-I variables studied, the change in level between the acute phase and 3 months post-stroke $(\triangle \mathrm{IGF}-\mathrm{I})$ showed the strongest association with $\mathrm{PA}$, and this association was retained in all the regression models. Further studies are needed to uncover whether the pre-stroke PA results in a priming effect that exerts beneficial effects with respect to the functional outcome or whether this is an effect of continuous post-stroke PA in those persons who were already physically active prior to the index stroke.

Supplementary Materials: Supplementary materials can be found at http://www.mdpi.com/2227-9059/8/3/52/s1.

Author Contributions: Conceptualization, N.D.Å., P.G., C.H., J.S., and J.I.; Methodology, N.D.Å., D.Å., C.J., J.S., and J.I.; Software, N/A; Validation, N.D.A.., D.A.., and J.I.; Formal Analysis, N.D. $\AA .$, and P.H.; Investigation, N.D.Å., C.B., K.J., and C.J.; Resources, N.D.Å., C.B., K.J., and C.J.; Data Curation, N.D.Å., C.B., K.J., and C.J.; Writing-Original Draft Preparation, N.D.A., P.H., C.J., J.S., and J.I.; Writing-Review and Editing, N.D.A.., P.H., G.G., D.Å., C.B., K.J., C.J., M.N., F.R.W., J.S., and J.I.; Visualization, N.D.Å., G.G., D.Å., C.J., J.S., and J.I.; Supervision, N.D.Å., J.S., C.J., and J.I.; Project Administration, N.D.Å.; Funding Acquisition, N.D.Å., J.I., C.B., C.J., and J.I. All authors have read and agreed to the published version of the manuscript.

Funding: This study was supported by the Swedish Medical Society (Svenska Läkaresällskapet), grants from the Swedish state under the agreement between the Swedish Government and the County Councils (ALF agreements: ALFGBG-720081; ALFGBG-147771; ALFGBG-722371; ALFGBG-719761, and ALFGBG-751111), the Swedish Research Council (2018-02543), the Swedish Heart Lung Foundation (20190203), the Swedish Stroke Association, the Göteborg Foundation for Neurological Research, and the Yngve Land, Rune and Ulla Amlöv, Edit Jacobson, Magnus Bergvall, Emelle, Lars Hierta, and John and Brit Wennerström foundations.

Acknowledgments: The authors thank research nurse Ingrid Eriksson for her excellent work and assistance in recruiting the participants and conducting the follow-up study, and Vincent Collins for making corrections to the language of the manuscript. We wish to thank Martin Adiels for statistical counseling regarding the models of regression.

Conflicts of Interest: The authors declare no conflict of interest.

\section{Abbreviations}

BMI Body mass index

IGF-I Insulin-like growth factor I

NIHSS National Institutes of Health Stroke Scale

PA Physical activity

SGPALS Saltin-Grimby Physical Activity Level 


\section{References}

1. Claesson, L.; Gosman-Hedström, G.; Johannesson, M.; Fagerberg, B.; Blomstrand, C. Resource utilization and costs of stroke unit care integrated in a care continuum: A 1-year controlled, prospective, randomized study in elderly patients: The Göteborg 70+ Stroke Study. Stroke 2000, 31, 2569-2577. [CrossRef]

2. Åberg, N.D.; Brywe, K.G.; Isgaard, J. Aspects of growth hormone and insulin-like growth factor-I related to neuroprotection, regeneration, and functional plasticity in the adult brain. Sci. World J. 2006, 6, 53-80. [CrossRef] [PubMed]

3. Denti, L.; Annoni, V.; Cattadori, E.; Salvagnini, M.A.; Visioli, S.; Merli, M.F.; Corradi, F.; Ceresini, G.; Valenti, G.; Hoffman, A.R.; et al. Insulin-like growth factor 1 as a predictor of ischemic stroke outcome in the elderly. Am. J. Med. 2004, 117, 312-317. [CrossRef] [PubMed]

4. Bondanelli, M.; Ambrosio, M.R.; Onofri, A.; Bergonzoni, A.; Lavezzi, S.; Zatelli, M.C.; Valle, D.; Basaglia, N.; degli Uberti, E.C. Predictive value of circulating insulin-like growth factor I levels in ischemic stroke outcome. J. Clin. Endocrinol. Metab. 2006, 91, 3928-3934. [CrossRef] [PubMed]

5. Åberg, D.; Jood, K.; Blomstrand, C.; Jern, C.; Nilsson, M.; Isgaard, J.; Aberg, N.D. Serum IGF-I levels correlate to improvement of functional outcome after ischemic stroke. J. Clin. Endocrinol. Metab. 2011, 96, E1055-E1064. [CrossRef]

6. De Smedt, A.; Brouns, R.; Uyttenboogaart, M.; De Raedt, S.; Moens, M.; Wilczak, N.; Luijckx, G.J.; De Keyser, J. Insulin-like growth factor I serum levels influence ischemic stroke outcome. Stroke 2011, 42, 2180-2185. [CrossRef]

7. Åberg, N.D.; Åberg, D.; Jood, K.; Nilsson, M.; Blomstrand, C.; Kuhn, H.G.; Svensson, J.; Jern, C.; Isgaard, J. Altered levels of circulating insulin-like growth factor I (IGF-I) following ischemic stroke are associated with outcome-A prospective observational study. BMC Neurol. 2018, 18, 106. [CrossRef]

8. Johnsen, S.P.; Hundborg, H.H.; Sørensen, H.T.; Orskov, H.; Tjønneland, A.; Overvad, K.; Jørgensen, J.O. Insulin-like growth factor (IGF) I, -II, and IGF binding protein-3 and risk of ischemic stroke. J. Clin. Endocrinol. Metab. 2005, 90, 5937-5941. [CrossRef]

9. Landin-Wilhelmsen, K.; Wilhelmsen, L.; Lappas, G.; Rosén, T.; Lindstedt, G.; Lundberg, P.A.; Bengtsson, B.A. Serum insulin-like growth factor I in a random population sample of men and women: Relation to age, sex, smoking habits, coffee consumption and physical activity, blood pressure and concentrations of plasma lipids, fibrinogen, parathyroid hormone and osteocalcin. Clin. Endocrinol. 1994, 41, 351-357.

10. Parekh, N.; Roberts, C.B.; Vadiveloo, M.; Puvananayagam, T.; Albu, J.B.; Lu-Yao, G.L. Lifestyle, anthropometric, and obesity-related physiologic determinants of insulin-like growth factor-1 in the Third National Health and Nutrition Examination Survey (1988-1994). Ann. Epidemiol. 2010, 20, 182-193. [CrossRef]

11. Mattlage, A.E.; Rippee, M.A.; Sandt, J.; Billinger, S.A. Decrease in Insulin-Like Growth Factor-1 and Insulin-Like Growth Factor-1 Ratio in the First Week of Stroke Is Related to Positive Outcomes. J. Stroke Cereb. Dis. 2016, 25, 1800-1806. [CrossRef] [PubMed]

12. Schwab, S.; Spranger, M.; Krempien, S.; Hacke, W.; Bettendorf, M. Plasma insulin-like growth factor I and IGF binding protein 3 levels in patients with acute cerebral ischemic injury. Stroke 1997, 28, 1744-1748. [CrossRef] [PubMed]

13. Rist, P.M.; Capistrant, B.D.; Mayeda, E.R.; Liu, S.Y.; Glymour, M.M. Physical activity, but not body mass index, predicts less disability before and after stroke. Neurology 2017, 88, 1718-1726. [CrossRef]

14. Oberlin, L.E.; Waiwood, A.M.; Cumming, T.B.; Marsland, A.L.; Bernhardt, J.; Erickson, K.I. Effects of Physical Activity on Poststroke Cognitive Function: A Meta-Analysis of Randomized Controlled Trials. Stroke 2017, 48, 3093-3100. [CrossRef] [PubMed]

15. Carro, E.; Trejo, J.L.; Busiguina, S.; Torres-Aleman, I. Circulating insulin-like growth factor I mediates the protective effects of physical exercise against brain insults of different etiology and anatomy. J. Neurosci. Off. J. Soc. Neurosci. 2001, 21, 5678-5684. [CrossRef]

16. Jood, K.; Ladenvall, C.; Rosengren, A.; Blomstrand, C.; Jern, C. Family history in ischemic stroke before 70 years of age: The Sahlgrenska Academy Study on Ischemic Stroke. Stroke 2005, 36, 1383-1387. [CrossRef] [PubMed] 
17. Olsson, S.; Jood, K.; Blomstrand, C.; Jern, C. Genetic variation on chromosome 9p21 shows association with the ischaemic stroke subtype large-vessel disease in a Swedish sample aged $\leq 70$. Eur. J. Neurol. 2011, 18, 365-367. [CrossRef] [PubMed]

18. Gatti, R.; De Palo, E.F.; Antonelli, G.; Spinella, P. IGF-I/IGFBP system: Metabolism outline and physical exercise. J. Endocrinol. Investig. 2012, 35, 699-707. [CrossRef]

19. Nindl, B.C.; Santtila, M.; Vaara, J.; Hakkinen, K.; Kyrolainen, H. Circulating IGF-I is associated with fitness and health outcomes in a population of 846 young healthy men. Growth Horm. IGF Res. 2011, 21, 124-128. [CrossRef]

20. Mattlage, A.E.; Rippee, M.A.; Abraham, M.G.; Sandt, J.; Billinger, S.A. Estimated Prestroke Peak $\mathrm{VO}_{2}$ Is Related to Circulating IGF-1 Levels during Acute Stroke. Neurorehabil. Neural Repair 2017, 31, 65-71. [CrossRef]

21. Reinholdsson, M.; Palstam, A.; Sunnerhagen, K.S. Prestroke physical activity could influence acute stroke severity (part of PAPSIGOT). Neurology 2018, 91, e1461-e1467. [CrossRef] [PubMed]

22. Ursin, M.H.; Ihle-Hansen, H.; Fure, B.; Tveit, A.; Bergland, A. Effects of premorbid physical activity on stroke severity and post-stroke functioning. J. Rehabil. Med. 2015, 47, 612-617. [CrossRef] [PubMed]

23. Saltin, B.; Grimby, G. Physiological analysis of middle-aged and old former athletes. Comparison with still active athletes of the same ages. Circulation 1968, 38, 1104-1115. [CrossRef] [PubMed]

24. Gray, L.J.; Ali, M.; Lyden, P.D.; Bath, P.M.; VISTA Collaboration. Interconversion of the National Institutes of Health Stroke Scale and Scandinavian Stroke Scale in acute stroke. J. Stroke Cerebrovasc. Dis. 2009, 18, 466-468. [CrossRef] [PubMed]

(C) 2020 by the authors. Licensee MDPI, Basel, Switzerland. This article is an open access article distributed under the terms and conditions of the Creative Commons Attribution (CC BY) license (http://creativecommons.org/licenses/by/4.0/). 